\title{
ILINCA ZARIFOPOL-JOHNSTON: ÎN CĂUTAREA LUI CIORAN... REGĂSINDU-SE PE SINE
}

\author{
ILINCA ZARIFOPOL-JOHNSTON: SEARCHING \\ FOR CIORAN... FINDING HERSELF
}

\section{Cristina GHENUȚĂ ${ }^{1}$}

https://doi.org/10.52744/9786062613242.19

Rezumat: Este o realitate că, pe lângă acei scrïtori români care au reuşit atât să se afirme într-o țară străină, cât şi să câştige o meritată apreciere în țara - mamă, mulți alți intelectuali talentați au rămas în mod nedrept necunoscuți cititorilor români. Este cazul Ilincăi Zarifopol-Johnston (scrïtoare - a tradus şi editat două opere de început ale eseistului-filosof E. M. Cioran, Pe culmile disperării şi Lacrimi şi sfinți - şi profesoară în cadrul Departamentului de literatură comparată la Indiana University, Bloomington), fiica mai mică a scrïtorului român Dinu Zarifopol, care a avut acelaşi destin tragic de a nu $i$ se acorda recunoaşterea pe care ar fi meritat-o, nici de către critici, nici de către cititori. Articolul de față, care oferă câteva informații generale despre viața şi scrierile Ilincăi Zarifopol-Johnston, este o încercare de a trezi interesul cititorului pentru acestă autoare, în special pentru lucrarea sa biografică, În căutarea lui Cioran.

Cuvinte cheie: Literatură; Traducere; Biografic; Filosof; Autor; Marginal; Cultură

\begin{abstract}
In addition to those Romanian writers who succeeded in gaining recognition both in a foreign country and in their country of birth, many others have unfairly remained unknown to the Romanian readers. Ilinca Zarifopol-Johnston is a writer, translator and editor of two early Romanian texts of the philosophical essayist E. M. Cioran, On the Heights of Despair and Tears and Saints, and a professor in the Department of Comparative Literature at Indiana University, Bloomington. She is the younger daughter of the Romanian writer Dinu Zarifopol, who himself did not receive popular or critical recognition for his work in Romania. The current article, which provides some general information about Ilinca Zarifopol-Johnston's life and academic work, is an attempt to arouse the reader's interest in this Romanian author's literary works, especially in her book entitled Searching for Cioran.
\end{abstract}

Keywords: Literature; Translation; Biographical; Philosopher; Author; Marginal; Culture

${ }^{1}$ Lector univ. dr., Universitatea Creştină Dimitrie Cantemir, cristina.ghenuta @ucdc.ro 


\section{Date biografice}

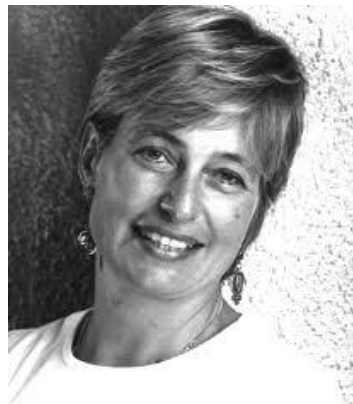

Ilinca Zarifopol-Johnston s-a născut pe 25.07.1952 la Bucureşti, într-o familie de intelectuali, de origine greacă, înrudită cu alte două renumite familii, Culianu şi Nanu. Tatăl, Dinu (Constantin Radu) Zarifopol, a fost avocat şi scriitor, autor al unui roman-fluviu, alcătuit din patru volume (însumând peste două mii de pagini) - Naufragiul, Moartea lui Levi, Şah la rege şi Crima generalului - scris pe ascuns, din perspectiva intelectualului-martor la instaurarea şi evoluția comunismului în țara noastră,

care consideră literatura de sertar ca pe o luptă împotriva „acestei silnicii”: „Am scris sub influența unui impuls de a evada din cotidianul sordid şi de a trăi într-o lume imaginară, care să reconstituie lumea mea de altădată din care am fost brutal izgonit." (Malamen 2000, 51-52)

Referindu-se la tetralogia scrisă de tatăl său, în cea de-a doua parte a cărții sale, Searching for Cioran (În căutarea lui Cioran) - parte intitulată sugestiv Memories of a Scoundrel (Amintirile unei Canalii) şi reprezentând, de fapt, un jurnal al autoarei (apelativul „canalie” sugerând, cel mai probabil, condiția biografului perceput drept un oportunist) - Ilinca Zarifopol-Johnston afirmă: „A scris la această carte timp de treizeci de ani. A fost hobby-ul său. A scris aşa cum alții jucau tenis sau golf sau vizionau filme. Ori de câte ori se simțea deprimat, se închidea în camera sa şi scria câteva pagini. Este versiunea romanțată a poveştii familiei sale, o saga ce acoperă perioada celor două războaie mondiale precum şi preluarea comunistă de după. Scriind, tatăl meu şi-a exorcizat demonii." (Zarifopol-Johnston 2009, 34)

Pe linie paternă, Ilinca Zarifopol-Johnston se înrudeşte cu matematicianul Neculai Culianu (junimist, apropiat al lui Titu Maiorescu şi membru corespondent al Academiei Române în perioada 1889-1915), cu Ioan Petru Culianu (strănepot al lui Neculai; scriitor, eseist şi istoric al religiilor; discipol şi protejat al lui Mircea Eliade), cu poetul Dimitrie Anghel şi cu criticul literar Paul Zarifopol.

Mama Ilincăi, Maria Zarifopol (Economu), i-a fost profesoară de pian Annei-Maria Grigorcea - strănepoată a Veronicăi Micle. Astfel, prin efortul comun al Mariei Zarifopol şi al primei sale fiice, Christina Zarifopol-Illias, patrimoniul literar românesc a primit un dar de o valoare inestimabilă: scrisori inedite ale lui Mihai Eminescu şi ale Veronicăi Micle, publicate în volumul Dulcea mea Doamnă/Eminul meu iubit. ${ }^{2}$

Ilinca Zarifopol-Johnston a absolvit Facultatea de Limbi Străine (specializarea engleză-germană), din cadrul Universității Bucureşti, în

${ }^{2}$ Apărut la Editura Polirom, 2000. 
anul 1975, iar lucrarea sa, Speech Acts of Permission in English, a câştigat premiul I la Colocviul Național Ştiințific Studențesc în 1976. După multiple intervenții ale unor politicieni americani, Ilincăi i s-a permis să emigreze în SUA în 1977, aceasta înscriindu-se într-un program pentru absolvenți la Universitatea Indiana din Bloomington. Ulterior, ea a absolvit un masterat în lingvistică (1980) şi un doctorat în literatură comparată (1990). Lucrarea sa, Victor Hugo, Charles Dickens şi Emile Zola, a câştigat The Esther L. Kinsley Outstanding Dissertation Award şi a fost publicată în 1955 cu titlul To Kill a Text: The Dialogic Fiction of Hugo, Dickens, and Zola (Delaware University Press).

In calitate de profesor - consilier la Universitatea Indiana, Ilinca Zarifopol-Johnston a câştigat premii pentru excelență în predare şi a creat diferite cursuri pentru studenții de la programele de licență (Beauty and the Beast: the Classics in Modern Adaptation) sau masterat (Exile or Prison? Writers under Repression in Eastern Europe and Africa). In anul 2003, Ilinca a fost visiting lecturer la Universitatea din Lisabona, Portugalia.

În ultimii ani de viață, interesul scriitoarei s-a îndreptat către România natală, mai ales în calitate de traducător în engleza americană şi editor al primelor texte scrise de eseistul francez de origine română E. M. Cioran. Astfel, la Editura Universității din Chicago, Ilinca publică traducerea cărții lui Cioran, Pe culmile disperării (On the Heights of Despair), în 1992, iar în 1995 apare Lacrimi şi Sfinți (Tears and Saints), datorită căreia obține nominalizarea la premiul pentru traduceri literare remarcabile, acordat de Modern Language Association.

Înainte de a muri, Ilinca începuse studiul biografic despre Cioran, intitulat inițial Portrait of the Philosopher as a Young Man (Portret al Filozofului la Tinerețe). În paralel, ea îşi scria propriile memorii, cu titlul she The Escape Artist: Memories of a Communist Girlhood (Artista Evadată: Memoriile unei Fete Crescute în Comunism), cuprinzând, în egală măsură, o relatare a prieteniei sale cu Cioran, la Paris. De asemenea, Ilinca se implicase în traducerea romanului în patru volume al tatălui său, cu titlul general The Moldavian Quartet (Cvartetul Moldovenesc), scris în anii '60 şi '70 şi publicat abia între 1994-1998, în urma căderii regimului comunist. Apariția tetralogiei i-a adus lui Dinu Zarifopol bine-meritatul statut de membru al Uniunii Naționale a Scriitorilor din România. Ilinca reuşise să traducă cel dintâi volum, The Last Boyar (Ultimul Boier) ${ }^{3}$, a cărui acțiune, plasată în timpul celui de-al doilea război mondial, se axează pe plecarea trupelor germane de pe moşia familiei sale, din Moldova, în vreme ce tot mai multe zvonuri şi temeri îşi făceau loc cu privire la avansarea armatelor ruseşti spre granița noastră de est.

3 Titlul original este Naufragiul. 
Din păcate, proiectele Ilincăi Zarifopol-Johnston au rămas neterminate deoarece, în 2005, la vârsta de 52 de ani, Ilinca s-a stins din viață, pierzând lupta împotriva cancerului.

\section{2. În căutarea lui Cioran}

Cartea a apărut în 2009, editată de soțul autoarei, Kenneth R. Johnston, cu un Cuvânt înainte semnat de criticul Matei Călinescu.

Din prefața, scrisă de Kenneth R. Johnston, aflăm că înainte să moară, în 2005, Ilinca aproape terminase biografia critică a filozofului Emil Cioran, în care îşi propusese să urmărească aspecte din viața lui, de la naştere (1911) până la plecarea acestuia în Franța în 1937, plecare ce a devenit definitivă începând cu anul 1941. Ni se spune că unele capitole au fost terminate de autoare însăşi (mai mult de trei sferturi), altele reconstruite de soțul său din notițe, ciorne sau documente păstrate în computer.

Pe parcursul acestui proiect, Ilinca a descoperit lucruri despre propriul său trecut şi s-a implicat în redarea în scris a propriilor experiențe trăite ca urmare a cercetării întreprinse. Drept urmare, scriitoarea începuse o autobiografie intitulată The Escape Artist (Artistul evadat). În mod evident, Cioran nu a fost un subiect uşor din cauza poziției sale de persona non grata în România comunistă. În plus, în perioada în care a trăit în România (1952-1977), Ilinca nu văzuse sau citise vreuna din operele lui Cioran. Însă, pentru Ilinca, adevărata dramă începe în 1995, după moartea lui Cioran, când Simone Boué, partenera de viață a lui filosofului român, rămâne executor literar al publicațiilor acestuia, iar Ilinca este prinsă în capcana numeroşilor oportunişti.

Tot din prefață aflăm cum a ajuns Ilinca să scrie biografia lui Cioran. La sugestia colegului şi prietenului său, criticul Matei Călinescu, Ilinca a fost de acord sa traducă două dintre cărțile în limba română ale lui Cioran, necunoscute în Occident. Au fost astfel publicate, la editura Universității din Chicago, On the Heights of Despair (Pe Culmile Disperarii - 1933), în 1992 şi Tears and Saints (Lacrimi şi Sfinți -1936), în 1995. La scurt timp după ce a început să lucreze la traduceri, Ilinca i-a cunoscut la Paris pe Cioran şi pe partenera lui de viață, Simone Boué, şi s-au împrietenit. Ilinca a fost una dintre puținele persoane cărora Cioran li se adresa şi în limba română, deşi vorbeau cu precădere în franceză. Ilinca a început să vadă în autoexilarea lui Cioran o reflexie şi anticipare a propriei autoexilări.

In articolul publicat sub titlul Found in Translation: The Two Lives of E. M. Cioran; Or How Can One Be a Comparatist? (Descoperit în Traducere: Cele Două Vieți ale lui E. M. Cioran; sau Cum Poate Cineva să fie Comparatist?) autoarea vorbeşte despre acest amplu proiect de cercetare a vieții şi operei lui Cioran, cu un impact major asupra vieții şi carierei autoarei. 
Aluzie evidentă la condiția marginalizatului, întrebarea „Cum poate cineva să fie persan?”- pusă cu uimire de un parizian, martor la spectacolul oferit de doi persani aflați în Oraşul Luminilor, în opera Scrisori Persane a lui Montesquieu - îşi are ecoul în Ispita de a exista, lucrare apărută în 1956: „Cum poate cineva să fie român?” se întreabă frustrat Cioran, încercând să-şi croiască un drum prin aceeaşi capitală a culturii mondiale. În calitate de cercetător al operei lui Cioran, Ilinca Zarifopol-Johnston reia întrebarea sub forma „Cum poate cineva să fie comparatist?”, ca o provocare la adresa normelor existente în practica literaturii comparate la nivel academic în SUA la început de secol XXI, întrucât, explică scriitoarea, „nu mă pot concentra exclusiv şi obiectiv asupra obiectului meu de studiu - Cioran şi cele două vieți ale sale - fără a include date legate de propria-mi viață, cea a unei românce care trăieşte în Statele Unite. (...) În traducerea procesului prin care Cioran se traduce pe sine din română în franceză, am înțeles că nu doar începusem un nou proiect biografic, ci totodată mi-am descoperit un nou sine autobiografic, transpunându-l pe Cioran în limba engleză la fel cum eu mă mutasem din România în America.” (Zarifopol-Johnston 2007, 20)

Fără îndoială, principalul obiectiv al Ilincăi a fost de a oferi cel mai bun răspuns la întrebarea „Cine este mai exact E. M. Cioran?”, întrebare la care se poate oferi un răspuns simplu: Cioran este filozoful francez de origine română, autor al unor opere cum ar fi Tratat de descompunere (1949), Ispita de a exista (1956), Căderea în timp (1964) sau Despre neajunsul de a te fi născut (1973). A fost bun prieten cu Henri Michaux, Samuel Beckett, Paul Celan şi Eugene Ionesco. A fost considerat „cel mai mare scriitor francez care a făcut cinste acestei limbi de la moartea lui Paul Valery”4, „un Socrate modern” 5 sau „,cea mai distinsă figură, continuator al tradiției lui Kirkegaard, Nietzche şi Wittgenstein"6. Moartea lui Cioran, în 1995 la Paris, a declanşat o avalanşă de articole în marile publicaţii franțuzeşti (Le Figaro, Le Monde, Paris Match sau Magazine Litteraire), precum şi spectacole de radio, televiziune şi interviuri, demonstrând retrezirea interesului față de viața şi opera marelui filosof.

Pe de altă parte, răspunsurile la întrebări legate de identitatea filosofului nu sunt nicidecum clare, ne explică Ilinca Zarifopol-Johnston. De exemplu, inițialele E. M. nu înseamnă Emil(e )Michel (aşa cum este catalogat de The Library of Congress), ci E. M. ca în cazul lui E. M. Foster. Aşadar, în mod intenționat, Cioran şi-a transformat primele două litere ale prenumelui său în inițiale, cu trimitere la bine-cunoscutul autor

\footnotetext{
4 St. John Perse.

5 Marc Fumaroli, profesor la College de France, membru al Academiei Franceze.

${ }^{6}$ Susan Sontag.
} 
englez, fapt ce sugerează atât ambițiile sale de scriitor, cât şi ambiguitățile legate de biografia sa. În viziunea Ilincăi, Cioran a avut „două vieți, două identități, două voci auctoriale: românul Cioran, un revoluționar mistic îmbibat cu idealurile romantismului politic şi francezul Cioran, care a părăsit România în 1937, exilându-se de bună-voie la Paris. În ajunul publicării primei sale opere în Franța, în 1949, tânărul Cioran, un autor necunoscut, un barbar (după cum se simțea) de la marginea Europei, a găsit în interiorul numelui său elementele care prefigurau faima pe care o va obține în epicentrul culturii europene - două litere obişnuite ridicate la înălțimea inițialelor renumite. Nu există alte legături între Cioran şi E. M. Foster. Noul nume integra conştietizarea propriei măreții, curând recunoscută prin recenziile favorabile apărute în presa franceză cu privire la opera Tratat de descompunere" (Zarifopol-Johnston 2007, 21). Aşadar, noul nume şi recunoaşterea de către presa franceză l-au transformat pe Cioran din barbar în autor francez, reuşind astfel să-şi depăşească condiția de marginalizat.

În urma traducerii celor două opere ale lui Cioran, Pe culmile disperării şi Lacrimi şi sfinți, Ilinca Zarifopol-Johnston se implică în scrierea unei biografii cu titlul inițial E.M. Cioran: Portrait of the Philosopher as a Young Man (Portret al Filozofului la Tinerețe), concentrându-se pe perioada de formare a lui Cioran (1928-1949), plină de „încercări şi erori, atingând culmi de o intensitate mistică, apoi plonjând în disperarea caracteristică sinucigaşului" (Zarifopol-Johnston 2007, 21). Incercarea autoarei de a determina modalitatea prin care tânărul român obscur s-a transformat în moralistul ironic şi stilat, admirat atât de mult în Franța, a dus la o dublă concentrare a acesteia, nu doar asupra revelației finale, ci şi asupra întregului proces de descoperire. Pe parcursul traducerii, Ilinca s-a simțit intrigată îndeosebi de faptul că Cioran elimina foarte mult din textul original, ajungând la concluzia că acesta de fapt îşi rescria operele din tinerețe: „mi se părea nu numai că era în căutarea unui stil, ci şi că fugea de „ceva” - „ceva” mai profund decât sentimentul de ruşine vis -a vis de aderarea la ideile fasciste, pe vreme când era tânăr." (Zarifopol-Johnston 2007, 21) Primul indiciu necesar descoperirii acelui „ceva” îi este oferit Ilincăi Zarifopol-Johnston de traducerea cărții Lacrimi şi sfinți. Ca şi Cioran, sfinții din cartea sa „fugeau de viață, de istorie, aspirând spre ceva mult mai măreț, dincolo de granițele lumii lor.” (Zarifopol-Johnston 2007, 21) Curând, Ilinca realizează că, la fel ca şi Conrad, Nabokov şi Stoppard, Cioran este un maestru al stilului într-o altă limbă decât cea maternă, iar stilul era scuza pe care o folosea atunci când îşi „ciopârțea” textele. În numeroase interviuri, Cioran mărturiseşte că cel mai important moment din cariera sa s-a petrecut în vara lui 1945, după terminarea războiului, într-un sat lângă Dieppe. În timp ce încerca să-l traducă pe Mallarmé în română, a 
avut o revelație: activitatea de traducere i s-a părut dintr-o dată absurdă. I s-a părut la fel de absurd să continue să scrie în limba română. Se afla în Franța de opt ani şi încă mai scria în română. Izbit de inutilitatea traducerii, Cioran a decis imediat să scrie în limba franceză şi, întorcându-se la Paris, începe să lucreze la prima sa carte în franceză, Précis de décomposition (Tratat de descompunere). Experiența lui Cioran este povestea iluminării şi a transformării, despre care scrie şi în Lacrimi şi sfinţi: „Toate marile transformări îşi au originea în brusca revelație a lipsei de sens" (ZarifopolJohnston 2007). La Cioran, revelația a constat în înțelegerea inutilităţii de a scrie în limba română şi de a fi român, iar concluzia Ilincăi este că „Cioran a înțeles «convertirea» la limba franceză ca pe un act de credință, nu printr-o trecere în lumea eternă a lui Dumnezeu, ci în lumea veşnică a stilului. Astfel, el nu a evadat în deşert sau într-o mănăstire, ci în singurătatea şi anonimatul celui mai civilizat oraş din lume, în care el, un scriitor necunoscut, a îndurat chinurile ascezei lingvistice." (Zarifopol-Johnston 2007, 25) Trecutul de care Cioran s-a rupt odată cu trecerea la franceză era cel legat de tinerețea sa: perioada anilor '30, ascensiunea fascismului în Europa de Vest şi regimul terorii lui Stalin în Rusia. Aceasta a fost perioada de aderare a lui Cioran la mişcarea cunoscută drept Garda de Fier, perioadă în care a scris Schimbarea la față a României, o utopie în care eseistul visează la o Românie ce are destinul Franței şi populația Chinei.

Treptat, Ilinca înțelege că pentru a reconstitui trecutul lui Cioran era necesar să citească textele acestuia mai degrabă ca pe nişte autobiografii ascunse decât ca pe nişte speculații filosofice, fiind atentă la contextul istoric în care au fost create şi la felul în care acele texte au fost influențate de respectivul context.

Din perspectiva comparatistului, Ilinca Zarifopol-Johnston vede în Cioran un caz special de cercetare: „Filosof şi om de litere, scriitor în două limbi, sprijinindu-se pe două culturi, a cărui proză reprezintă o țesătură intertextuală alcătuită din rescrieri ale propriilor sale texte, rescrieri ale unei întregi literaturi, de la mistica medievală, moralişti francezi de secol optsprezece până la Dostoievski, Schopenhauer, Kirkegaard şi Nietzsche." (Zarifopol-Johnston 2007, 32) În opinia Ilincăi Zarifopol-Johnston, Cioran face parte din mişcarea pan-europeană, pornind de la misticism până la postmodernism, putând fi astfel cu uşurință comparat cu o mulțime de scriitori implicaţi în mişcări politice şi sociale, scriitoarea menționându-i pe Martin Heidegger, Paul de Man, T. S. Eliot, Ezra Pound sau Jean Paul Sartre.

Apropierea Ilincăi de Cioran se face inițial datorită proiectului de traducere a celor două cărți pentru care era deja pregătită, ca urmare a absolvirii unei facultăți de specialitate în România (engleză-germană), a unui masterat în lingvistică în SUA şi, nu în ultimul rând, prin faptul că vorbea nativ limba română. Ulterior, Ilinca devine interesată de 
personalitatea eseistului, şi, după ce îl cunoaşte personal, experiența lui de viață „devine relevantă pentru mine într-un mod mai degrabă organic decât artificial, din moment ce împărtăşeam câteva aspecte biografice: experiența de a vorbi două limbi, experiența politică a totalitarismului (legătura lui cu fascismul, a mea cu comunismul), acelaşi fundament religios: ortodoxismul, precum şi experiența exilului de bună-voie. $\mathrm{Nu}$ o dată mi-am pus aceeaşi întrebare: „cum poate cineva să fie român?” (Zarifopol-Johnston 2007, 32) Şi nu în ultimul rând, Ilinca este fascinată de Cioran, deoarece acesta aparține unui trecut cultural şi politicRomânia interbelică - ce a fost în mod deliberat deformat şi fals prezentat de către comunişti: ,„̂n consecință, nu ştiam prea multe despre acel trecut - al meu, al lui, al țării noastre. Cufundându-mă în trecutul lui, îmi cercetam propriul trecut şi astfel căutându-l pe Cioran am început să mă caut pe mine însămi, o călătorie de redescoperire a originilor mele culturale care acum ia forma unui alt proiect, autobiografic." (ZarifopolJohnston 2007, 32)

În ceea ce priveşte încadrarea operei Ilincăi Zarifopol-Johnston în categoria studiilor de literatură comparată din SUA, scriitoarea este de părere că există evidente legături cu scrierile tinerei generații de comparatişti ai anilor '9o despre care se vorbeşte în raportul Bernheimer intitulat „Literatura Comparată la sfârşit de secol” (1993). Solicitând o redefinire a obiectivelor şi metodelor disciplinei, raportul susţine că fenomenele literare nu mai constituie punctul central al acestei discipline, propunând în schimb crearea literaturii şi a modalităților de contextualizare a literaturii în domeniile mai largi ale discursului, culturii, ideologiei, rasei şi genului, acestea constituind obiecte de studiu mai potrivite (Zarifopol-Johnston 2007, 32). Mai mult decât atât şi mai important, în opinia Ilincăi, este faptul că raportul reaşază traducerea acolo unde îi este locul, respectiv în centrul literaturii comparate: „Literatura comparată îşi propune să explice, atât ceea ce se pierde, cât şi ceea ce se câştigă prin traducere de către sisteme de valori distincte aparținând unor culturi, discipline şi instituții diferite. Mai mult, comparatistul ar trebui să-şi asume responsabilitatea localizării în spaţiu şi timp a practicilor pe care le studiază. De unde mă adresez, din ce tradiție/ tradiții sau căror tradiții mă opun? Cum traduc o realitate europeană sau sud-americană sau africană în realitatea culturală nord-americană sau cum traduc America de Nord într-un alt context cultural?” (ZarifopolJohnston 2007, 33)

În ciuda tuturor acestor aspecte, Ilinca Zarifopol-Johnston mărturiseşte faptul că un proiect ca cel legat de opera lui Cioran - un scriitor aflat la granița dintre central şi marginal - încă întâmpina rezistență din partea mediului academic, coordonat de „centre de putere învechite” 
(old centres of power). Însă, ca şi Cioran, Ilinca Zarifopol-Johnston înțelesese că nu mai era necesară o „disecție” pentru a ajunge în centru, deoarece centrul şi marginile sunt ceva relativ, nişte realităţi interschimbabile. În situația în care, din perspectiva Uniunii Europene de după 1989, sau mai exact a lumii de după Războiul Rece, începe să se pună din ce în ce mai mult problema dominaţiei, a hegemoniei americane, Ilinca Zarifopol-Johnston este de părere că experiența oamenilor marginalizați şi valoarea disciplinelor comparate care îi studiază pe aceştia ar trebui aduse în prim-plan, nu aruncate în umbră, deoarece „cel aflat în centru nu numai că poate, ci trebuie să reinventeze marginile, aşa cum ne învață parabola lui Kafka, Un Mesaj Imperial: întotdeauna cineva visează să atingă centrul şi, visându-l, îl reinventează” (ZarifopolJohnston 2007, 37).

\section{Bibliografie}

\section{Surse primare:}

Zarifopol-Johnston, Ilinca. (2009). Searching for Cioran. Bloomington: Indiana University Press.

Zarifopol-Johnston, Ilinca. (2007). "Found in Translation: The Two Lives of E. M. Cioran; Or How Can One Be a Comparatist?” Comparative Literature Studies, 44(1-2).

\section{Surse secundare:}

Bradatan, Costica. (2009). In Shambles (Ilinca Zarifopol-Johnston, Searching for Cioran), TLS October, (www.academia.edu)

Obituary: Ilinca Zarifopol-Johnston (https://newsinfo.iu.edu/news-archive/1825.html)

Malamen, Iolanda. (2000). „Dialog cu Dinu Zarifopol” Vatra, nr. 1/200o. 